\title{
Personality as the Basis for Theoretical Predilections
}

\author{
John A. Johnson \\ Pennsylvania State University
}

\author{
Christopher K. Germer \\ The Cambridge Hospital, Harvard Medical School
}

\author{
Jay S. Efran and Willis F. Overton \\ Temple University
}

\begin{abstract}
Four groups of behavioral scientists with divergent theoretical persuasions-- 43 sociobiologists, 25 behaviorists, 35 personality psychologists, and 16 human developmentalists—showed significantly different mean scores on two measures of philosophical assumptions: the World Hypothesis Scale (WHS) and the Organicism-Mechanism Paradigm Inventory (OMPI). The OMPI, which appears to be more psychometrically sound than the WHS, showed in 12 additional groups of subjects ( $N=$ 622 ) consistent correlations with self-report and peer ratings of personality, intellectual and interpersonal style, and occupational interests. Taken together, the two studies suggest that behavioral scientists' philosophical presuppositions (e.g., whether reality is better described by stable, isolated elements or changing holistic patterns; and whether persons are passive and reactive or purposive and active) may mirror their views of themselves.
\end{abstract}

This article empirically addresses two issues lying at the juncture of psychology and the philosophy of science. It first addresses a claim from modern philosophy of science, namely, that all scientific theories (including psychological theories) necessarily assume a position on the three fundamental philosophical concerns: existence, knowledge, and values (Bahm, 1974). In addition, psychological theories presuppose a philosophy of personhood (Martin, 1982). The second issue considered in this article is the validity of a psychology of science (Singer, 1971). The recent discovery that scientists are people (McCain \& Segal, 1988, chap. 8) suggests that scientists' personalities may play a role in what is often regarded as a purely rational and empirical enterprise.

The notion that psychological theories presuppose philo-

Portions of this research were presented by John A. Johnson at the 92nd Annual Convention of the American Psychological Association in Toronto, Ontario, Canada, August 1984, and at the 95th Annual Convention of the American Psychological Association in New York, August 1987. Other portions of this research were presented by Christopher K. Germer at the 53rd Annual Meeting of the Eastern Psychological Association in Baltimore, April 1982.

The research was partially supported by College of Liberal Arts Faculty Research Fund and Liberal Arts Commonwealth Educational System Fund grants to John A. Johnson, and by a National Institutes of Health Grant RR07115 to Christopher K. Germer, Jay S. Efran, and Willis F. Overton.

Thanks go to our colleagues, N. Kumaraswamy of Kasturba Medical School in Monipal, India, for providing the Nigerian and Indian data, and Tanja Lamovec of the University of Ljubljana in Ljubljana, Yugoslavia, for providing the Yugoslavian data. We thank David Buss, David Bakan, Robert Hogan, M. Brewster Smith, and several anonymous reviewers for their comments on earlier drafts of this article, and Michael Gerg for assisting in the data analyses.

Correspondence concerning this article should be addressed to John A. Johnson, Department of Psychology, Pennsylvania State University, DuBois Campus, College Place, DuBois, Pennsylvania 15801. sophical commitments has received perhaps the widest attention in life span developmental psychology (but see also Slife, 1987). Life span textbooks (e.g., Fitzgerald, 1986; Lerner \& Hultsch, 1983; Santrock \& Bartlett, 1986), following Pepper's (1942) schema of philosophical root metaphors, often suggest that social learning theory is based on mechanistic assumptions (the world is like a machine), whereas cognitive-developmental theory is based on organismic assumptions (the world is like a living organism). Although logical arguments linking theories with philosophical assumptions abound (Overton, 1975, 1976; Reese \& Overton, 1970), to date there is no evidence that living, practicing behaviorists or Piagetian developmentalists actually adhere to given philosophical worldviews. This article presents such evidence.

The second issue - that the thinking of rational beings such as philosophers and scientists can interact with elements of personality-troubles some people. We regard this state of affairs as an unavoidable fact of life, a necessary consequence of the fact that sensing, thinking, and personality all coexist within persons (cf. Block, Buss, Block, \& Gjerde, 1981; Wardell \& Royce, 1975). This article demonstrates that individual differences in basic philosophical assumptions covary in a meaningful way with personal traits, as measured by scores on psychological scales and inventories.

\section{Pepper's Taxonomy of Worldviews}

Philosopher Stephen Pepper's (1942) book, World Hypotheses, has over the past 45 years attracted a small yet fervent band of advocates. They claim that the beauty of Pepper's book lies in its simple but comprehensive taxonomy of four philosophical worldviews. Formism is predicated on similarities among events in the universe. Mechanism assumes that the universe, like a machine, can be analyzed into parts that can be understood in isolation from the whole. Organicism suggests that the universe is best understood as a system of complex, interrelated 
processes, such as those evident in living organisms. Contextualism assumes that reality consists of textured layers constructed by observers, as rope is constructed from strands of thread woven together.

At the foundation of each worldview lies what Pepper calls a root metaphor. The cornerstone of contextualism, for example, is the metaphor, "The universe is stranded rope." Metaphors are neither true nor false; hence, attraction to one of Pepper's root metaphors may be more a matter of personal taste than of logical or empirical considerations. If personal taste is a reflection of one's personality dispositions (Knapp, 1964), we might expect meaningful personality differences among persons preferring different Pepperian worldviews. Our choice of Pepper's taxonomy of philosophical worldviews was also bolstered by our being able to build upon recent efforts to measure preference for Pepper's worldviews (Bethel, 1975; Germer, Efran, \& Overton, 1982; Harris, Fontana, \& Dowds, 1977; Kramer, Goldston, \& Kahlbaugh, 1987).

Harris et al. describe the development of the World Hypothesis Scale (WHS) to measure Pepper's four worldviews. Positive results from their work include the following three findings: (a) Persons sharing compatible world hypotheses experienced greater satisfaction in dyadic relationships, (b) clients who participated in psychotherapies based on world hypotheses compatible with their own perceived the therapies as more appealing, and (c) subjects endorsing different worldviews showed theoretically meaningful preferences for different occupations.

The World Hypothesis Scale shows a number of weaknesses, however. All the statements assessing a particular world hypothesis end in nearly identical wording. For example, all the mechanism statements (which reflect the assumption of causality) end with, "Thus there is a specific reason for . . ." The four scales show substantial intercorrelations; for example, organicism and mechanism correlate $(r=-.60)$, and formism and contextualism correlate $(r=-.64$; Germer et al. found intercorrelations of -.47 and -.48 ). This suggests that organicism/mechanism and formism/contextualism might be better operationalized as bipolar continua rather than as independent dimensions.

The World Hypothesis Scale also failed to show meaningful correlations with a battery of personality tests (Machiavellian Scale-Christie \& Geis, 1970; Social Desirability-Crowne \& Marlowe, 1960; Dogmatism-Rokeach, 1960; and Locus of Control-Rotter, 1966). Perhaps this is because these tests, used typically for narrow research purposes, are irrelevant to Pepper's constructs. However, in a later study (Wilson, 1980) all four scales on the WHS correlated essentially zero with all three scales from the Psycho-Epistemological Profile (Royce, Mos, \& Kearsley, 1975).

More recently, Germer et al. (1982) attempted to improve upon Harris et al.'s (1977) effort to operationalize Pepper's world hypotheses by constructing the Organicism-Mechanism Paradigm Inventory (OMPI). The 26 forced-choice items on the OMPI cover both philosophical areas (ontology, epistemology, personhood, analysis and causality, change, dynamics, and methodology) and matters of practical concern for ordinary people (conjugal, parenting, occupational, legal, and other interpersonal relationships).

Despite the complexity and diversity of items, the OMPI scale showed good internal consistency, with a Guttman split-half coefficient of .86 and a Cronbach alpha coefficient of .76. A 3week retest showed a stability coefficient of .77 . Thus, the format, content validity, and reliability of the OMPI are improvements over the WHS. Germer et al. found that the OMPI, like the WHS, was associated with occupational preference but failed to correlate with scales like Locus of Control and Social Desirability. More recently, Nolf (1986) found that OMPI scores followed a predictable pattern with coping styles, and Kramer et al. (1987) found that OMPI scores correlated as predicted with their own measure of Pepper's worldviews.

Whatever the relative strengths and shortcomings of the WHS and OMPI, both have yet to demonstrate primary validity (cf. Gough, 1965): an association between scale scores and criteria implied directly by the theory underlying the scales. The WHS and OMPI were designed to assess philosophical worldviews that underlie scientific theorizing. Therefore, the WHS and OMPI-if they validly measure worldviews-should predict scientists' theoretical preferences and alignment with research paradigms. This article therefore first describes a study that examines the relationship between WHS and OMPI scores and the actual activities of behavioral scientists.

The second study describes additional research on the relation between OMPI scores and personality. We believe that previous research on worldviews and personality has failed to reveal significant relations because the domain of personality was not adequately sampled. The second study samples the full range of personality dispositions in order to assess personality traits that ought to be associated with preferences for different worldviews.

\section{Study 1}

\section{Subjects}

Subjects were chosen to represent different approaches to the study of human behavior. A sample of 100 sociobiologists was chosen by drawing names from the editorial staff of and contributors to the journal Ethology and Sociobiology during the period 1979-1984. In a discussion of Pepper's ideas, sociobiologist Daniel Freedman (1979, pp. 3-6) suggested that most sociobiologists lean toward organicism as a world hypothesis, although some who focus at a molecular level may be more mechanistically inclined.

A sample of 87 Skinnerian behaviorists was chosen from the editorial staff of and list of guest editors for The Journal of $A p$ plied Behavior Analysis from the year 1984. According to Reese and Overton (1970), behaviorism aligns with the mechanistic world hypothesis more closely than any other modern school of thought in the social sciences.

A sample of 79 personality psychologists was chosen from the editorial masthead and list of reviewers for the personality section of the Journal of Personality and Social Psychology during the tenure of section editor Robert Hogan. Personality psychologists, who emphasize internal over external causes of behavior are typically antibehavioristic. Hogan (1976), for example, has claimed that the behavioral point of view deserves no space in a personality textbook. Personality psychologists would 
be expected to endorse a formism that stresses similarities among persons (providing a basis for typologies) and stability and continuity of the self (a common assumption among personologists).

Finally, a select group of 45 human developmentalists were chosen because they had in some way demonstrated publicly a strong or even radical affiliation with organicism or contextualism (two world hypotheses that Pepper says are closely related). This group was more diverse than the first three and was drawn from many sources: the editorial staff of Human Development, contributors to a book honoring the organicist Heinz Werner, and an interdisciplinary department of human development, among others.

\section{Method}

In the spring of 1986 , subjects were mailed a package containing a letter explaining the study, an informed consent form, a list of eight validity-check questions to confirm that their current self-description was congruent with their public research record, copies of the World Hypothesis Scale (Bethel, 1975) and the Organicism-Mechanism Paradigm Inventory (Germer et al., 1982), and a posted return envelope. By November 1986, completed questionnaires had ceased to come in, and the data from respondents were analyzed. Return rates were as follows: sociobiologists, 47/100 (47\%); behaviorists, 26/87 (30\%); personologists, $42 / 79$ (53\%); and human developmentalists, 19/45 (42\%).

The total number of cases was reduced slightly by incomplete responses to the WHS and OMPI and by failure of subjects to describe themselves as expected on the set of validity questions. To remain in the study, subjects had to affirm the following statements: sociobiologist: I would describe myself as an evolutionary biologist; behaviorist: I would describe myself as a behaviorist; personologist: I would describe myself as a personologist; and human developmentalist: Heinz Werner has influenced my thinking. Usable cases for the OMPI dropped to 43,25 , 35 , and 16 , respectively, and to $39,25,34$, and 14 for the WHS.

Several statistical analyses followed. Scores on the OMPI, four scales of the WHS, and answers to the eight validity questions (scored no $=1$, not sure $=2$, yes $=3$ ) were intercorrelated and subjected to a principle components factor analysis. Next, differences on the OMPI and four WHS scales were compared by analysis of variance. Finally, group membership was predicted by discriminant analysis, using the OMPI and WHS together and then each separately.

\section{Results}

The correlations between the OMPI and four WHS scales indicated that the low end of the OMPI is related to the WHS Mechanism and Formism scales $(r \mathrm{~s}=-.43$ and -.24 , respectively), and the high end of the OMPI is related to the WHS Organicism and Contextualism scales ( $r=.32$ in both cases). These results are predictable, given that the OMPI is supposed to measure mechanism at the low end and organicism at the high end; Pepper (1942) said that formism is related to mechanism, whereas organicism is related to contextualism.

The intercorrelations among the four WHS scales are also consistent with theory and past research. Mechanism and formism correlate $(r=.27)$, and organicism and contextualism correlate $(r=.18, p<.05$, two-tailed). Mechanism and formism correlate negatively with organicism and contextualism (all $r \mathrm{~s}$ about -.60$)$.
The principle components factor analysis of intercorrelations among the eight validity questions, OMPI, and four WHS scales, shown in Table 1, revealed five factors with eigenvalues greater than unity. The first factor appears to be a method factor with substantial positive loadings from the OMPI, Organicism, and Contextualism; negative loadings from Formism and Mechanism; and negligible loadings from the eight validity questions. Each of the next four factors is cleanly defined by two of the eight validity questions. Factor 2 is defined by large loadings on statements one would expect the personality psychologists to make ("I would describe myself as a personologist" and "Gordon Allport has influenced my thinking"). In a similar fashion, Factor 3 represents the views of the behaviorists; Factor 4, the sociobiologists; and Factor 5, the human developmentalists.

Secondary loadings on Factors 2 through 5 from the OMPI and WHS reflect the theoretical preferences of the four samples. As predicted, the Personality factor is marked by a positive loading on Formism and a negative loading on Mechanism. The Behaviorism factor has a large negative loading on the OMPI (indicating mechanism) and a positive loading on the WHS mechanism scale. The Sociobiology factor is marked by a positive loading on Organicism and a negative loading on Contextualism. The Human Development factor is partly defined by a positive loading on Organicism and a negative loading on Formism.

Differences among the four samples on the OMPI and WHS can also be seen through analysis of variance. All five $F$ ratios were significant at at least the .05 level. The details on the differences among the groups on the scales, shown in Table 2 , follow the predicted patterns. Human developmentalists scored highest on the OMPI, behaviorists, the lowest. The personality psychologists received the highest scores on Formism; the behaviorists, on Mechanism; and the human developmentalists, on Organicism and Contextualism.

Three discriminant analyses were conducted. When the OMPI and four WHS scales were allowed to enter a discriminant function according to their ability to contribute to a significantly greater discriminating function $(F=1$ to enter the function), the OMPI entered first, followed by Formism and Mechanism. The other two WHS scales did not meet statistical requirements for entry, apparently because of their significant inverse correlations with Formism and Mechanism. This OMPI-Formism-Mechanism function classified $37.84 \%$ of the cases correctly.

An attempt to enter only WHS scales into a discriminant analysis again found only Mechanism and Formism contributing significantly to a discriminating function. The MechanismFormism function classified $39.29 \%$ of the cases correctly. Finally, when the OMPI was used alone in a discriminant analysis, it classified $37.82 \%$ of the cases correctly.

\section{Discussion}

The results of the analyses presented demonstrate for the first time significant primary validity for both the OMPI and the WHS. Scores on both instruments showed predicted relations with the actual behavior of scientists (written statements of the- 
Table 1

Factor Analysis of Self-Descriptions and World Hypotheses Scales

\begin{tabular}{|c|c|c|c|c|c|}
\hline \multirow{2}{*}{ Self-description validity items } & \multicolumn{5}{|c|}{ Factor loadings } \\
\hline & 1 & 2 & 3 & 4 & 5 \\
\hline Charles Darwin has influenced my thinking. & & & & 72 & \\
\hline I would describe myself as an evolutionary biologist. & & & & 80 & \\
\hline I would describe myself as a behaviorist. & & & 80 & & \\
\hline B. F. Skinner has influenced my thinking. & & 24 & 80 & & \\
\hline I would describe myself as a personologist. & & 87 & & & \\
\hline Gordon Allport has influenced my thinking. & & 88 & & & \\
\hline I would describe myself as a systems theorist. & & & & & 82 \\
\hline Heinz Werner has influenced my thinking. & 21 & 24 & -31 & & 62 \\
\hline Organicism-Mechanism Paradigm Inventory (OMPI) & 44 & & -54 & & \\
\hline \multicolumn{6}{|l|}{ World Hypothesis Scale (WHS) } \\
\hline Formism scale of WHS & -78 & 28 & & & -31 \\
\hline Mechanism scale of WHS & -79 & -35 & 20 & & \\
\hline Organicism scale of WHS & 67 & & & 25 & 31 \\
\hline Contextualism scale of WHS & 83 & & & -23 & \\
\hline
\end{tabular}

Note. Only factor loadings greater than .20 are reported.

oretical preference, publishing and editing in specific journals, participation in symposia, etc.).

Results from the present study, coupled with results from past research, indicate that the OMPI is probably superior to the WHS in several respects. The significant scale intercorrelations on the WHS indicate that it has redundancies; two scales at most seem sufficient to capture the variance in the WHS. The OMPI appears to be more efficient, measuring mechanism and formism at the low end and organicism and contextualism at the high end.

Additional considerations favor the OMPI over the WHS. It is shorter and therefore takes less time to complete. From the few unsolicited negative comments from subjects, most concerned the repetitive nature and general inadequacy of the WHS. Far more incomplete WHSs were returned than incomplete OMPIs. Finally, the OMPI alone correctly classified about

Table 2

Analyses of Variance for Worldview Scores Across Subject Groups

\begin{tabular}{|c|c|c|c|c|c|}
\hline \multirow[b]{2}{*}{ Variable } & \multicolumn{4}{|c|}{ Subject group } & \multirow[b]{2}{*}{$F$ ratio } \\
\hline & Socbio & Behav & Person & Devel & \\
\hline \multicolumn{6}{|l|}{ OMPI } \\
\hline$N$ & 43 & 25 & 35 & 16 & $F(3,115)=16.32^{* *}$ \\
\hline$M$ & 18.7 & 14.8 & 18.7 & 23.1 & \\
\hline$S D$ & 3.3 & 4.1 & 4.4 & 2.0 & \\
\hline \multicolumn{6}{|l|}{ WHS } \\
\hline$N$ & 39 & 25 & 34 & 14 & \\
\hline \multicolumn{6}{|l|}{ Formism } \\
\hline$M$ & $\underline{30.0}$ & 27.7 & 33.0 & 22.4 & $F(3,108)=6.54^{* *}$ \\
\hline$S D$ & 7.3 & 9.1 & 7.9 & 6.4 & \\
\hline \multicolumn{6}{|l|}{ Mechanism } \\
\hline$M$ & $\underline{35.9}$ & 39.2 & 32.0 & $\underline{28.8}$ & $F(3,108)=7.19^{* *}$ \\
\hline$S D$ & 6.5 & 8.1 & 8.8 & 7.5 & \\
\hline \multicolumn{6}{|l|}{ Organicism } \\
\hline$M$ & 28.4 & 26.7 & $\underline{27.1}$ & $\underline{34.3}$ & $F(3,108)=3.30^{*}$ \\
\hline$S D$ & 7.5 & 10.6 & 6.2 & $\frac{2.1}{7.1}$ & \\
\hline \multicolumn{6}{|c|}{ Contextualism } \\
\hline$M$ & 25.8 & 26.4 & 27.9 & $\underline{34.5}$ & $F(3,108)=3.33^{*}$ \\
\hline$S D$ & $\overline{7.9}$ & 9.4 & 9.6 & $\overline{10.5}$ & \\
\hline
\end{tabular}

Note. Underlined means indicate smallest difference significant at the .05 level for a Scheffe posttest. Socbio = sociobiologists; Behav = behaviorists; Person $=$ personologists; Devel $=$ human developmentalists. OMPI $=$ Organicism-Mechanism Paradigm Inventory, and WHS = World Hypothesis Scale.

${ }^{*} p<.05 .{ }^{* *} p<.001$. 
Table 3

Outline of Mechanistic and Organismic Paradigms

\begin{tabular}{lc}
\multicolumn{1}{c}{ Mechanism } & \multicolumn{1}{c}{ Organicism } \\
\hline Stability & Ontology \\
Elementarism & Holism \\
& Epistemology \\
Objectivism & Interactionism \\
Realism & Constructivism \\
& Explanation \\
Reductionistic analysis & Synthetic understanding of \\
& organization \\
Parts related in antecedent- & Functions served by structures \\
consequence & \\
& \\
Reactive & View of Persons \\
Passive & Active \\
Determined by environment & Purposive \\
No inherent functions & Autonomous \\
No true development toward & Inherent functions \\
endpoints & Creative, changing, progressive \\
Separate from social & Integrated into social \\
environment & environment \\
\hline
\end{tabular}

Note. From the Organicism-Mechanism Paradigm Inventory: Toward the Measurement of Metaphysical Assumptions by C. K. Germer, J. S. Efran, and W. F. Overton. Paper presented at the 53rd Annual Meeting of the Eastern Psychological Association, Baltimore, Maryland, April 1982. Adapted by permission.

the same percentage of subjects as a combined OMPI-WHS function or a WHS function. These considerations suggest that additional research on worldviews and personality should be conducted with the OMPI rather than the WHS.

Before turning to the study of personality and worldviews, we would like to reiterate the purpose of the foregoing study. The study does not imply that we can or should determine if someone is, for example, a behaviorist by examining his or her OMPI or WHS scores. Asking social scientists outright about their theoretical allegiances or observing their research activities is easier and far more accurate than administering questionnaires. The utility of the study lies in the demonstration of meaningful links between one's theoretical predilections and one's fundamental philosophical presuppositions, as measured by the WHS and OMPI.

\section{Study 2}

\section{Introduction}

To clarify how personality would be expected to be related to preference for a mechanistic or organismic worldview, we will describe in more detail the nature of these worldviews. A summary of the differences between the two worldviews is found in Table 3.

Mechanism. The root metaphor of the mechanistic worldview is the machine, and its dynamics are essentially Newtonian. The universe is understood as being composed of discrete parts that are inherently at rest. The static parts and relations between them are the basic units to which all objects and events are ultimately reducible. The epistemology of this view asserts that reality is external to the knower, and the knower comes to copy or reflect the world to various degrees of precision. The object of knowledge is therefore distinguishable from the subject.

The ideal form of explanation in mechanism is a reductionistic analysis of parts and their functional relations. The parts are related in antecedent-consequent interactions or chains of interactions. The scientific methodology generated by the mechanistic worldview is empirical, disciplinary, and stresses the precedence of sense data over concepts.

Persons in the mechanistic worldview are represented as reactive, passive, and completely determined by their environments. They have no inherent functions, and development (progression toward endpoints) is mere appearance. Their personalities consist of quantifiable stimulus-response contingencies, and persons are distinct from their environments. Historically, this image of personhood stems from John Locke's tabula rasa (Allport, 1955). It became refined by the 18 th century empiricists Berkeley and Hume, by James and John Stuart Mill in the 19 th century, and is presently manifest in the work of modern behaviorists.

Organicism. The root metaphor of the organismic worldview is the living organism, and its dynamics are more Lorenzian (1977) than Newtonian. The universe is inherently active and changing. Any apparent stability is the product of rational concepts. Such concepts are holistic and give meaning to an organization of parts. The epistemology of this position maintains that, although the world and the knower are unified, the world can be known by apparent rational activity. Thus, the known world is an active construction of the knower-in-context.

The ideal form of explanation in organicism is a synthetic understanding of organized complexity. Functions or goals are defined in relation to structures that serve them. The scientific methodology generated by the organismic worldview is rational, ecological, and stresses the precedence of concepts over sense data. It seeks to establish rules of order and organization prior to empirical validation.

Persons in the organismic worldview are seen as active, changing, purposive, and autonomous. They have inherent psychological functions and structures that give meaning to behavior. Development is a reality, and persons are self-differentiating, creative, and symbolic. Each individual has a unique personality system, but is also an integral part of a larger interpersonal system. Historically, the model of personhood as active and changing was formulated by Leibniz in the late 17 th century, was developed by Kant and Hegel, and is presently seen in Piaget's developmental psychology, general systems theory, and in aspects of the "third force" psychologies of Maslow and Rogers.

Note that within each worldview, the suppositions about personhood are perfectly consistent with the suppositions about the universe in general. Our prediction, therefore, is that people will tend to behave in a manner that is consistent with their philosophical worldview. That is, they will present themselves on personality scales and will be described by others in a fashion 
that is isomorphic with their preferred root metaphor. Because mechanism views persons as reactive, determined, ontologically isolated from their environments, and homeostatic, mechanists will present themselves as reactive, determined, isolated, and homeostatic. Because organicism views persons as active, autonomous, ontologically integrated with the environment, and self-transforming, organicists will present themselves as active, autonomous, integrated with their environment, and self-transforming.

\section{Method}

Subjects. Twelve groups of subjects $(N=622)$ were used in Study 2. The subjects were assessed at different points in time between 1980 and 1987. For convenience and clarity of presentation, we have numbered the groups from 1 to 12 , in the same order in which they appear in Table 4: (1) 40 Yugoslavian introductory psychology students (5 male, 35 female); (2) 50 Temple University undergraduate students (25 male, 25 female) who volunteered to take a battery of tests in return for feedback; (3) 64 Pennsylvania State University (Penn State) students (27 male, 37 female) enrolled in an undergraduate course in personal growth; (4) 100 adults ( 49 male, 51 female) chosen by stratified sampling to represent proportions of demographic variables compiled by the Bureau of the Census, U.S. Department of Commerce, between 1978 and 1980; (5) 24 Penn State adult students ( 7 male, 17 female) enrolled in a summer session introductory psychology course; (6) 56 Penn State students (30 male, 26 female) enrolled in a mental health course; (7) 78 Penn State students ( 38 male, 40 female) enrolled in an introductory psychology course; (8) 79 Penn State students ( 31 male, 48 female) enrolled in an introductory psychology course; (9) 15 applicants (all male) for the position of police officer in a small city; (10) 40 Nigerian engineering students ( 36 male, 4 female); (11) 50 Nigerian medical students ( 44 male, 6 female); and (12) 26 Indian dental students ( 15 male, 11 female). All foreign students were English-speaking. All groups completed the Organicism-Mechanism Paradigm Inventory, described in the next section. Each group also completed some but not all of the additional psychological tests described below.

Organicism-Mechanism Paradigm Inventory. The OMPI (available from the authors) is a 26 -item, forced-choice inventory designed to measure an individual's preference for one of two worldviews outlined by Overton (1976) and Reese and Overton (1970). The labels for these worldviews, mechanism and organicism, were adopted from Bertalanffy's (1968) general systems theory. The worldviews also correspond to Pepper's (1942) world hypotheses of the same name. Items cover both philosophical areas (ontology, epistemology, etc.) and areas of everyday concern (conjugal relationships, parenting, etc.).

Overton's discussions were intended to describe paradigms from which psychologists operate. Yet, everyone is a psychologist in the sense that we are all interested in understanding and predicting each other's behavior (Heider, 1958; G. A. Kelly, 1955). Therefore the lay psychologist will have a set of presuppositions about human behavior that, if more or less organized and consistent, will resemble the mechanistic or organismic paradigms.

Inner- and other-directedness. Sample 6 was administered Johnson's (1987a) Inner-Directedness and Other-Directedness scales. These scales were derived from items identified in an earlier factor analysis (Collins, Martin, Ashmore, \& Ross, 1973). Organicism, which holds that persons are active and autonomous, was expected to correlate with Inner-Directedness. Mechanism, which views persons as reactive and determined, was predicted to correlate with other-directedness.

Personal and social identity. Jonathan Cheek's Aspects of Identity Scales (AIS; Cheek \& Briggs, 1982; Cheek \& Hogan, 1983; Hogan \&
Cheek, 1983) consists of two short, Likert-format scales to measure a person's involvement in personal identity (personal values, emotions, thoughts) and social identity (popularity, interpersonal relationships, group memberships). The AIS was administered to Samples 5 and 6 in the present study. Because personal identity is conceptually similar to inner-directedness, whereas social identity is conceptually related to other-directedness (Hogan \& Cheek, 1983), the pattern of relationships between the Identity scales and the OMPI was expected to be similar to that for the Inner- and Other-Directedness scales.

Myers-Briggs Type Indicator. A short form of the Myers-Briggs Type Indicator (MBTI; Myers, 1962) was administered to Samples 3, 5, 6, and 8 to assess the relationship between OMPI scores and resemblance to Jung's (1923) psychological types. The short scales correlated .86, $.84, .74$, and .82 with the longer EI, SN, TF, and JP scales, respectively (Johnson, 1984).

Of the four indexes on the MBTI, the Sensing-Intuition index seems most relevant to mechanistic versus organismic worldviews. Sensing types, who enjoy work involving facts, details, routine, and standard procedures, were expected to endorse a mechanistic worldview. Intuitive types, who are imaginative, original, and prefer novel, complex problems, were expected to hold an organismic worldview. We also made predictions about the Judging-Perceiving dimension. Judging types are critical, prudent, guarded, conservative, planful, and organized and therefore might be expected to score toward the low (mechanistic) end of the OMPI. Perceptive types are open, spontaneous, insightful, changeable, impulsive, and disorderly and therefore might be expected to score toward the high (organismic) end of the OMPI.

Edwards Personal Preference Inventory. The Yugoslavian students (Sample 1) took the Edwards Personal Preference Schedule (EPPS; Edwards, 1959). The ipsative scoring of the EPPS tends to produce inconsistent correlates (Anastasi, 1976). Nevertheless, if correlations with the OMPI are to be found, the dynamic, self-determining nature of organicism might lead us to expect the OMPI to correlate in a positive direction with needs for Autonomy, Exhibition, Dominance, and Change. The OMPI might also be expected to correlate positively with Consistency, because research indicates that consistency in self-description is associated not with orderliness and compulsiveness but with personal and social integration (Johnson, 1981). The passive, reactive, conforming nature of mechanism leads us to expect negative correlations between the OMPI and Deference, Order, and Abasement.

Sensation-Seeking Scale. Sample 1 also took Form IV of the Sensation-Seeking Scale (SSS; Zuckerman, 1979). The SSS was originally developed to test the idea that differences in individuals' neurophysiology create differences in individuals' optimal levels of stimulation, excitation, or activation. Zuckerman's $(1979,1983,1985)$ research program has supported this contention. The SSS currently yields five scores: General Sensation-Seeking, Thrill- and Adventure-Seeking, Experience-Seeking, Disinhibition, and Boredom Susceptibility. The organismic individual's interest in change and personal growth leads us to expect positive correlations between the SSS subscales and the OMPI.

Holland's VPI and SDS and the Strong-Campbell Interest Inventory. The Self-Directed Search (SDS; Holland, 1985b), Vocational Preference Inventory (VPI; Holland, 1985c), and Strong-Campbell Interest Inventory (SCII; Campbell \& Hansen, 1981; Campbell \& Holland, 1972) measure an individual's preferences for six types of occupations (Holland, 1985a). Samples 3 and 6 completed the VPI, Samples 5 and 8 completed the SDS, and Sample 2 completed the SCII for the present study.

Two of Holland's types, Conventional and Artistic, represent antithetical personality styles that have implications for a wide range of human affairs (Johnson, 1983; Johnson \& Hogan, 1981). Conventional types, who are conservative, custodial, and conforming, were expected to hold 
a mechanistic worldview. Artistic types, who are progressive and innovative, were expected to hold an organismic world view.

California Psychological Inventory. Samples 5, 6, 7, and 8 completed the California Psychological Inventory (CPI; Gough, 1975). The CPI has been described as the best available inventory for measuring normal differences in personality (E. L. Kelly, 1965; Kleinmuntz, 1967). Factor analyses of the CPI have revealed four major factors (Megargee, 1972): Adjustment, Interpersonal Competence, Intellectual Flexibility, and Conventionality. We predicted first of all that the CPI scales marking the Intellectual Flexibility factor would show the strongest relation to the organismic end of the OMPI, because organicism is purportedly more cognitively complex than mechanism (Germer et al., 1982), and the organismic worldview implies flexibility and change. We also predicted that the CPI scales marking interpersonal competence would be associated with organicism, because the organismic worldview implies harmonious integration between part (person) and whole (social group).

Learning Style Inventory. Sample 3 completed Kolb's (1976) Learning Style Inventory (LSI). Like the Myers-Briggs Type Indicator, the LSI derives from Jungian type theory. The LSI is scored with four short scales that are then combined into two principal bipolar scales: abstract conceptualization versus concrete experience (AC-CE) and active experimentation versus reflective observation (AE-RO). The two combined scales, $\mathrm{AC}-\mathrm{CE}$ and $\mathrm{AE}-\mathrm{RO}$, have acceptable levels of reliability (about .80) across diverse samples, whereas, of the shorter scales, only CE shows acceptable reliability.

Kolb's (1976) data on the AE-RO scale failed to show a clear, consistent pattern of relations with other variables. Therefore, no predictions were made concerning the relation between AE-RO and the OMPI. $\mathrm{AC}-\mathrm{CE}$, on the other hand, was found to correlate with Intuition on the Myers-Briggs SN index, with creativity scores, and with an interest in theoretical subjects such as physics, chemistry, and mathematics (Kolb, 1976). High scorers on the OMPI (organismic individuals) were expected to score in the direction of abstract conceptualization rather than concrete experience, again because organicism is purportedly more cognitively complex and abstract than mechanism (Germer et al., 1982).

Bipolar Adjective Rating Scales. Subjects in Sample 8 rated themselves and had three persons who knew them well rate them with the Bipolar Adjective Rating Scales (BARS; Johnson, 1987b). Subjects in Sample 7 chose one person who knew them well to rate them with the BARS. The BARS consists of forty-nine 7-point, Likert-scale adjective pairs designed to representatively sample the universe of personality trait descriptors. For both samples, peer ratings were returned confidentially to the investigators to encourage honesty. The 49 BARS scales can either be clustered into seven superordinate scales representing broad dimensions that have recurred persistently during the past 40 years of factor-analyzing personality scores (Hogan, 1986; Norman, 1986) or used individually to provide a complete but more fine-grained analysis of personality (Johnson, Cheek, \& Smither, 1983).

Wide Range Vocabulary Test. The Wide Range Vocabulary Test (WRVT; Atwell \& Wells, 1937) measures verbal intelligence. The WRVT was completed by the three foreign student samples: 10,11, and 12. WRVT scores were expected to correlate with organicism because this worldview is cognitively more complex and abstract than mechanism (Germer et al., 1982; Kramer, 1983).

Analyses. Means and standard deviations on the OMPI were computed for all groups tested and were compared with OMPI means from the four groups tested in Study 1. We expected no group to outscore the human developmentalists tested in the first group, yet we predicted that most groups would score higher than the prototypically mechanistic behaviorists tested previously.

Correlations were computed between the OMPI and measures described previously. In summary, we expected high scores on the OMPI (organismic orientation) to be associated with inner-directedness, per-
Table 4

Normative Data for the Organicism-Mechanism

Paradigm Inventory (OMPI)

\begin{tabular}{lrrrrr}
\hline \multicolumn{1}{c}{ Sample } & $N$ & $\mathrm{M}$ & $\mathrm{F}$ & OMPI & \multicolumn{1}{c}{$S D$} \\
\hline Human developmentalists & 16 & 10 & 6 & 22.26 & 2.83 \\
Sociobiologists & 43 & 30 & 13 & 18.85 & 4.15 \\
Personologists & 35 & 32 & 3 & 18.55 & 3.28 \\
Yugoslavian psychology students (1) & 40 & 5 & 35 & 17.70 & 2.09 \\
Temple University students (2) & 50 & 25 & 25 & 17.34 & 4.17 \\
1985 personal growth class (3) & 64 & 27 & 37 & 17.16 & 3.40 \\
U.S. standardization sample (4) & 100 & 49 & 51 & 16.07 & 4.00 \\
1984 adult students (5) & 24 & 7 & 17 & 16.04 & 3.45 \\
1983 mental health students(6) & 56 & 30 & 26 & 15.96 & 3.43 \\
1985 introductory psychology & & & & & \\
$\quad$ students(7) & 78 & 38 & 40 & 15.45 & 3.44 \\
1984 introductory psychology & & & & & \\
$\quad$ students (8) & 79 & 31 & 48 & 14.92 & 3.64 \\
Behaviorists & 25 & 21 & 4 & 14.79 & 4.05 \\
Police applicants (9) & 15 & 15 & 0 & 14.33 & 3.20 \\
Nigerian engineering students (10) & 40 & 36 & 4 & 12.45 & 2.88 \\
Nigerian medical students(11) & 50 & 44 & 6 & 11.78 & 3.28 \\
Indian dental students(12) & 26 & 15 & 11 & 11.69 & 2.94 \\
\hline
\end{tabular}

Note. Samples without numbers in parentheses are from Study 1 ; samples from Study 2 are numbered (in parentheses) as described in Study 2. $M=$ male; $F=$ female.

sonal identity, intuition, artistic interests, intellectual openness and flexibility, verbal intelligence, and an abstract learning style. Low scores on the OMPI (mechanistic orientation) were expected to be associated with other-directedness, social identity, sensing, conventional interests, intellectual rigidity, and a concrete learning style.

\section{Results}

OMPI means and standard deviations for all groups tested in this and the previous study are presented in Table 4 . As predicted, the human developmentalists received the highest OMPI score, indicating that they are the most organismically inclined. The mean score for behaviorists, as predicted, was one of the lowest of all groups, pointing to their mechanistic orientation. The lowest mean scores of all groups, however, were found for the three third-world student samples.

Table 5 presents OMPI correlates for all personality scales and inventories (except the BARS) administered to more than one sample, allowing one to examine the replicability of findings. The vocational inventories were completed by five samples, the MBTI and CPI by four samples, and the AIS by two samples.

The Personal Identity scale of the AIS showed the predicted positive correlation with the OMPI in Sample 6 but not in Sample 5 . The Social Identity scale failed to show the predicted correlation with the mechanistic end of the OMPI in either Sample 5 or 6.

The predictions for the longer personality inventories were borne out for the most part. Organicism was associated with intuition, and mechanism with sensing in three out of four samples that completed the MBTI. Also, organicism correlated with perceiving, and mechanism with judging in two out of these four samples. High scores on the OMPI (organismic ori- 
Table 5

Replicated Organicism-Mechanism Paradigm Inventory-Personality Correlates

\begin{tabular}{|c|c|c|c|c|c|c|}
\hline \multirow[b]{2}{*}{ Personality scale } & \multicolumn{6}{|c|}{ Sample group } \\
\hline & $2^{\mathrm{a}}$ & $3^{\mathrm{b}}$ & $5^{c}$ & $6^{\mathrm{d}}$ & $7^{\mathrm{e}}$ & $8^{f}$ \\
\hline Personal identity & & & 11 & $42^{* *}$ & & \\
\hline Social identity & & & 05 & -19 & & \\
\hline \multicolumn{7}{|l|}{ Myers-Briggs Type Indicator } \\
\hline Introversion & & -01 & 16 & 03 & & 02 \\
\hline Intuition & & 21 & $75^{* * *}$ & $56^{* * *}$ & & $55^{* * *}$ \\
\hline Feeling & & 20 & 03 & 14 & & 11 \\
\hline Perceiving & & $38^{* *}$ & $41^{*}$ & 17 & & 10 \\
\hline \multicolumn{7}{|l|}{ Holland vocational types ${ }^{\mathrm{g}}$} \\
\hline Realistic & 08 & -14 & 02 & -13 & & 04 \\
\hline Investigative & 15 & 05 & 31 & 19 & & $32^{*}$ \\
\hline Artistic & 20 & $22^{*}$ & 13 & $41^{* *}$ & & $19^{*}$ \\
\hline Social & -13 & 05 & -23 & $24^{*}$ & & 08 \\
\hline Enterprising & -10 & 15 & 08 & -02 & & -02 \\
\hline Conventional & $-30^{*}$ & -10 & 01 & -01 & & -05 \\
\hline \multicolumn{7}{|l|}{ California Psychological Inventory } \\
\hline Dominance & & & 09 & $33^{* *}$ & $29 * *$ & $33^{* * *}$ \\
\hline Capacity for status & & & 06 & $34^{* *}$ & $33^{* *}$ & $33^{* *}$ \\
\hline Sociability & & & 31 & $26^{*}$ & 16 & 16 \\
\hline Social presence & & & 32 & $32^{* *}$ & 04 & 03 \\
\hline Self-acceptance & & & $36^{*}$ & $33^{* *}$ & 13 & 06 \\
\hline Empathy & & & 16 & $46^{* * *}$ & $25^{*}$ & $22^{*}$ \\
\hline Well-being & & & -08 & 20 & 08 & 12 \\
\hline Responsibility & & & -31 & $25^{*}$ & $21^{*}$ & $29^{* *}$ \\
\hline Socialization & & & -20 & -02 & 06 & 02 \\
\hline Self-control & & & $-35^{*}$ & -01 & -07 & -03 \\
\hline Tolerance & & & 07 & $46 * * *$ & 10 & $20^{*}$ \\
\hline Good impression & & & -08 & -10 & 02 & 16 \\
\hline Communality & & & $-46^{*}$ & 04 & $19^{*}$ & 15 \\
\hline Achievement via conformance & & & -28 & $35^{* *}$ & 13 & 04 \\
\hline Achievement via independence & & & 14 & $48^{* * *}$ & 16 & 15 \\
\hline Intellectual efficiency & & & -05 & $45^{* * *}$ & $28^{* *}$ & $22^{*}$ \\
\hline Psychological mindedness & & & 25 & 08 & 18 & 14 \\
\hline Flexibility & & & $61^{* * * *}$ & $38^{* * *}$ & 10 & $35^{* * *}$ \\
\hline Femininity & & & $-47^{*}$ & 16 & 07 & 06 \\
\hline
\end{tabular}

Note. Decimal points are omitted from all correlation coefficients.

${ }^{a}$ Group 2 are 50 Temple University students. ${ }^{b}$ Group 3 are 64 Pennsylvania State University (Penn State) personal growth students. ${ }^{c}$ Group 5 are 24 Penn State adult students. ${ }^{\mathrm{d}}$ Group 6 are 56 Penn State mental health students. ${ }^{\mathrm{e}}$ Group 7 are 78 Penn State introductory psychology students. ${ }^{\mathrm{f}}$ Group 8 are 79 Penn State introductory psychology students. ${ }^{\mathrm{g}}$ Holland types are measured by the Vocational Preference Inventory in Samples 3 and 6, by the Self-Directed Search in Samples 5 and 8 , and by the Strong-Campbell Interest Inventory in Sample 2.

${ }^{*} p<.05 . \quad{ }^{* *} p<.01 .{ }^{* * *} p<.001$.

entation) were associated in three out of four samples that completed the CPI, with two scales marking intellectual flexibility (Intellectual Efficiency and Flexibility) and with three scales marking interpersonal effectiveness (Dominance, Capacity for Status, and Empathy).

The correlations between the OMPI and Holland vocational type scales, reported in Table 5, are less consistent and of a lower magnitude than the OMPI-personality correlations. The OMPI-Artistic correlations reached statistical significance in three of the five samples that took a vocational inventory; converting the $r \mathrm{~s}$ to $z \mathrm{~s}$, averaging, and converting back to $r$ produced a mean correlation of .24. The expected significant correlation between Conventional vocational interests and the mechanistic end of the OMPI was found in only one sample $(r=-.30$ in Sample 2).

BARS correlates of OMPI scores are presented in Table 6.
The OMPI correlated significantly, as expected, with the broad mentality and novelty dimensions in both Samples 7 and 8 . The individual adjective scale correlations showed that OMPI high scorers (organismic individuals) described themselves as imaginative, aesthetic, creative, well-read, industrious, leaderlike, warm, liberal, unorthodox, changeable, complex, experimenting, and persevering. These self-perceptions were confirmed about half of the time by peer ratings. OMPI low scorers (mechanistically inclined individuals), on the other hand, described themselves as down-to-earth, inartistic, ordinary, simple, unlettered, easy-going, follower, cold, conservative, traditional, predictable, conventional, and quitting.

The Wide Range Vocabulary Test was administered only to the Indian and Nigerian student samples. The WRVT did not correlate with the OMPI at the .05 level $(.05<p<.10$ in two groups, and $p>.10$ in the third). This result fails to provide a 
Table 6

Self and Peer Adjective Rating Correlates of the Organicism-Mechanism Paradigm Inventory

\begin{tabular}{|c|c|c|c|c|c|c|c|}
\hline \multirow[b]{2}{*}{ Scale } & \multicolumn{3}{|c|}{ Correlations } & \multirow[b]{2}{*}{ Scale } & \multicolumn{3}{|c|}{ Correlations } \\
\hline & Self & Peer A & Peer B & & Self & Peer A & Peer B \\
\hline Mentality & $38^{* *}$ & $25^{*}$ & $37^{* *}$ & Poise (Continued) & & & \\
\hline Imaginative-Down-to-earth & $36^{* *}$ & $22^{*}$ & 14 & Poised-Nervous & 00 & -03 & -03 \\
\hline Aesthetic-Inartistic & $33^{* *}$ & 14 & $32^{* *}$ & Confident-Worried & -05 & 04 & 12 \\
\hline Creative-Ordinary & $43^{* *}$ & 17 & $38^{* *}$ & Cheerful-Depressed & 07 & -02 & 00 \\
\hline Intellectual-Unreflective & 18 & 09 & 17 & Self-assured-Shy & 05 & 04 & -04 \\
\hline Complex-Simple & $22^{*}$ & $27^{*}$ & 07 & Healthy-Frail & 02 & 03 & -12 \\
\hline Clever-Naive & -04 & 00 & 14 & Composed-Moody & -02 & -01 & -01 \\
\hline Well-read-Unlettered & $21^{*}$ & $22^{*}$ & $32 * *$ & & & & \\
\hline \multirow[t]{2}{*}{ Learned-Unlearned } & 03 & -06 & 15 & Novelty & $36^{* *}$ & 07 & $20^{*}$ \\
\hline & & & & Liberal-Conservative & $29 * *$ & 06 & $29 * *$ \\
\hline Power & $20^{*}$ & 13 & 18 & Unorthodox-Traditional & $34^{* *}$ & 04 & 07 \\
\hline Active-Passive & -03 & 09 & 02 & Changeable-Predictable & $29 * *$ & 00 & 07 \\
\hline Vigorous-Unenergetic & 03 & $22^{*}$ & $25^{*}$ & Modern-Old-fashioned & -02 & -02 & 10 \\
\hline Energetic-Leisurely & 11 & -05 & 04 & Progressive-Preserving & 17 & -04 & 15 \\
\hline Ambitious-Apathetic & 08 & 10 & 17 & Experimenting-Conventional & $36^{* *}$ & 09 & 10 \\
\hline Enterprising-Unambitious & 14 & 08 & 13 & Forward-looking-Reminiscent & 06 & 14 & -05 \\
\hline Industrious-Easy-going & $19^{*}$ & 07 & $29^{* *}$ & & & & \\
\hline Leaderlike-Follower & $30^{* *}$ & 16 & 07 & Sociality & 05 & -09 & 09 \\
\hline \multirow[t]{2}{*}{ Bold-Timid } & 08 & 08 & -04 & Talkative-Quiet & 03 & -05 & 10 \\
\hline & & & & Sociable-Solitary & -02 & -12 & 06 \\
\hline Likeableness & -10 & -01 & 07 & Outgoing-Reserved & 04 & -08 & 03 \\
\hline Good natured-Irritable & 07 & 17 & 04 & Extraverted-Introverted & 10 & -05 & 11 \\
\hline Tactful-Blunt & -14 & -19 & 07 & & & & \\
\hline Warm-Cold & $19^{*}$ & 04 & 00 & Conventionality & -05 & 08 & 15 \\
\hline Diplomatic-Outspoken & -10 & -08 & 06 & Responsible-Undependable & -07 & 11 & $25^{*}$ \\
\hline Cooperative-Stubborn & -09 & 10 & 06 & Trustworthy-Unreliable & -09 & 04 & 14 \\
\hline Tolerant-Impatient & -05 & 01 & 02 & Conscientious-Negligent & 04 & 15 & 14 \\
\hline Agreeable-Critical & -04 & -01 & 01 & Careful-Careless & -17 & 03 & 11 \\
\hline \multirow{2}{*}{ Empathic-Self-centered } & -14 & -03 & 13 & Persevering-Quitting & $20^{*}$ & 13 & -02 \\
\hline & & & & Rule-abiding-Rule-avoiding & -11 & -02 & -02 \\
\hline Poise & 03 & 05 & -03 & & & & \\
\hline Calm-Anxious & -01 & 11 & -02 & & & & \\
\hline Relaxed-Tense & -04 & 05 & -13 & & & & \\
\hline
\end{tabular}

Note. Adjective scales are scored in direction of first adjective in each pair. Positive correlation indicates that organicism is associated with first adjective trait in the pair; negative correlation indicates that mechanism is associated with first adjective trait in the pair. Decimals are omitted from all correlation coefficients. Self column refers to self-ratings on BARS in Sample $8(N=79)$. Peer A column refers to average of three peer ratings on BARS in Sample $8(N=79)$ averaged ratings. Peer B column refers to peer ratings on BARS in Sample $7(N=78)$.

$* p<.05 * * p<.01$.

strong cross-cultural replication of the OMPI-verbal intelligence relationship reported earlier by Germer et al. (1982).

The remaining descriptions of results concern scales administered to only 1 of the 12 samples. The OMPI correlated, as expected, with the AC-CE scale of the Learning Style Inventory, $r=.27, p<.05$; nonsignificantly $(p=-.01)$ with the AERO scale and individual active experimentation $(r=-.10)$ and reflective observation $(r=-.05)$ components. The correlation with AC-CE was apparently due primarily to the significant negative correlation between the OMPI and concrete experience, $r=-.38, p<.01$. Abstract conceptualization correlated a nonsignificant .05 with the OMPI.

The mechanistic end of the OMPI correlated significantly, as expected, with other-directedness, $r=-.42, p<.01$, but nonsignificantly with inner-directedness $(r=.14)$.

The SCII, unlike the SDS and VPI, contains, in addition to the six general Holland themes, scales for individual occupations. The SCII was administered only to the Temple University students (Sample 2). The OMPI correlated consistently with occupations whose primary component was Artistic. These correlations, with the SCII-Holland codes indicated, are as follows: Advertising Executive (AE, .31); Architect (AIR, .29); Art Teacher (A, .31); Commercial Artist (A, .29); Fine Artist (A, .39); Interior Decorator (AE, .40); Lawyer (AI, .26); Musician (A, .33); and Photographer (A, .42). Correlations above 32 were significant at the .01 level; all others were significant at the .05 level. The only other significant positive correlations were with occupational scales that had a secondary Artistic component in the SCII-Holland code, namely, Occupational Therapist (RAS, .27); College Professor (IA, .24); Psychologist (IA, .29); and Sociologist (IA, .27). Among all Conventional occupations, only Banker $(C,-.29)$ and Dental Assistant $(C,-.23)$ showed significant predicted associations with the mechanistic end of the OMPI.

In the Yugoslavian student sample (Sample 1), the OMPI showed predicted correlations with the following EPPS scales: 
Order $(r=-.27, p<.05)$, Exhibition $(r=.30, p<.05)$, and Consistency $(r=.46, p<.46)$. The OMPI also correlated significantly with General Sensation-Seeking $(r=.37, p<.05)$ but nonsignificantly with the specific aspects of sensation-seeking (all $r$ s about .20).

\section{Discussion}

The OMPI measure of philosophical worldviews correlated pervasively but not perfectly consistently with a variety of personality variables. Strongest support for OMPI-personality correlations came from personality inventories that sampled the full domain of personality (MBTI, CPI, BARS). Organismic individuals were consistently found to be more intellectual, aesthetic, intuitive, innovative, and socially skilled than mechanistic individuals. Mechanistic individuals were found to be more concrete, down-to-earth, sense-oriented, ordinary, and socially hesitant.

Results from the vocational inventories were somewhat less consistent, although the Artistic theme did seem to be related to organicism. On the BARS, OMPI high scorers (organismic individuals) described themselves as intellectual, ambitious, and sensation-seeking (high mentality, power, and novelty), all of which are general aspects of the artistic syndrome (Johnson, 1983). The individual adjective correlates pinpoint the specific aspects of the Artistic and Conventional personality syndromes associated with high and low OMPI scores; in other words, high OMPI scorers are imaginative, whereas low scorers are downto-earth, and so forth.

In summary, the evidence demonstrates clearly disparate personality portraits for persons holding a mechanistic worldview and persons endorsing an organismic worldview. Mechanistically oriented persons (e.g., behaviorists) tend to be orderly, stable, conventional, and conforming, objective and realistic in their cognitive style, and interpersonally passive, dependent, and reactive. This personality description is consistent with the mechanistic worldview, which assumes an ontology of stability and elementarism, an epistemology of objectivism and realism, and a view of persons as reactive, passive, estranged from-yet determined by-their environments, who fail to develop progressively.

In contrast, organismically inclined individuals (e.g., human developmentalists) tend to be fluid, changing, creative, and nonconforming. They tend to be participative and imaginative in their cognitive style. They are active, purposive, autonomous, and individualistic, yet integrated into their interpersonal environment. This personality portrait is consistent with the organismic worldview, which assumes an ontology of change and holism, an epistemology that is interactive and constructivistic, and a view of persons as active, purposive, autonomous, creative, integrated into the social matrix, who progressively develop toward goals. In short, individuals' personalities mirror their overall philosophical worldviews.

\section{General Discussion}

Modern philosophy of science tells us that every scientific theory must assume a set of philosophical assumptions. Study 1 supports this position empirically by demonstrating that behavioral scientists with different theoretical predilections (assessed by their public research activities) adhere to the different philosophical worldviews measured by the World Hypothesis Scale and the Organicism-Mechanism Paradigm Inventory.

Study 2 demonstrates that when the domain of personality is adequately sampled, scores on the OMPI are associated in a meaningful way with self- and peer descriptions of personality traits. More specifically, persons' basic philosophical presuppositions (e.g., whether reality is better described by stable, isolated elements or changing holistic patterns; and whether persons are passive and reactive or purposive and active) mirror their views of themselves.

We believe that these findings are consistent with past discussions of the philosophy and psychology of science as reported by Allport (1955), Atwood and Tomkins (1976), Coan (1968, 1979), Hart (1982), Krasner and Houts (1984), Kuhn (1962), Royce (1974), Rychlak (1968), Stolorow and Atwood (1979), Tomkins (1965), and Young (1975). The upshot of both the present study and previous research is that scientists exhibit individual differences in beliefs, attitudes, assumptions, cognitive style, and methodological preferences, all of which constitute aspects of their overall personality style.

Two considerations limit this interpretation of our data. Our data from the behavioral scientists do not sample the full range of theoretical positions in the social sciences and say nothing about theoretical positions in the physical sciences. Furthermore, the personality-OMPI correlational data come from nonscientist samples. Only the collection of worldview as well as personality data from larger and more varied samples of scientists can answer these concerns.

\section{References}

Anastasi, A. (1976). Psychological testing (4th ed.). New York: Macmillan.

Allport, G. W. (1955). Becoming. Basic considerations for a psychology of personality. New Haven, CT: Yale University Press.

Atwell, C. R., \& Wells, F. L. (1937). Wide Range Vocabulary Test, Form $B$. New York: The Psychological Corporation.

Atwood, G. E., \& Tomkins, S. S. (1976). On the subjectivity of personality theory. Journal of the History of the Behavioral Sciences, 12, 166177.

Bahm, A. J. (1974). Metaphysics: An introduction. New York: Barnes and Noble.

Bethel, M. (1975). The world hypotheses scale: A study of world organizing systems. Dissertation Abstracts International, 36, 1911B1912B. (University Microfilms No. 75-21,966)

Bertalanffy, L. von. (1968). Organismic psychology and systems theory. Barre, MA: Barre Publishing Co.

Block, J., Buss, D. M., Block, J. H., \& Gjerde, P. F. (1981). The cognitive style of breadth of categorization: The longitudinal consistency of personality correlates. Journal of Personality and Social Psychology, 40,770-779.

Campbell, D. P., \& Hansen, J.-I. (1981). Manual for the SVIB-SCII. Stanford, CA: Stanford University Press.

Campbell, D. P., \& Holland, J. L. (1972). Applying Holland's theory to Strong's data. Journal of Vocational Behavior, 2, 353-376.

Cheek, J. M., \& Briggs, S. R. (1982). Self-consciousness and aspects of identity. Journal of Research in Personality, 16, 401-408. 
Cheek, J. M., \& Hogan, R. (1983). Self-concepts, self-presentations, and moral judgments. In J. Suls \& A. Greenwald (Eds.), Psychological perspectives on the self (Vol. 2, pp. 249-273). Hillsdale, NJ: Erlbaum.

Christie, R., \& Geis, F. (1970). Studies in Machiavellianism. New York: Academic Press.

Coan, R. W. (1968). Dimensions of psychological theory. American Psychologist, 23, 715-722.

Coan, R. W. (1979). Psychologists: Personal and theoretical pathways. New York: Irvington.

Collins, B. E., Martin, J. C., Ashmore, R. D., \& Ross, L. (1973). Some dimensions of the internal-external metaphor in theories of personality. Journal of Personality, 41, 471-492.

Crowne, D. P., \& Marlowe, D. (1960). A new scale of social desirability independent of psychopathology. Journal of Consulting Psychology, 24, 349-354.

Edwards, A. L. (1959). Edwards Personal Preference Schedule. New York: Psychological Corporation.

Fitzgerald, J. M. (1986). Lifespan human development. Belmont, CA: Wadsworth.

Freedman, D. G. (1979). Human sociobiology: A holistic approach. New York: Free Press of MacMillan.

Germer, C. K, Efran, J. S., \& Overton, W. F. (1982, April). The Organicism-Mechanism Paradigm Inventory: Toward the measurement of metaphysical assumptions. Paper presented at the 53rd Annual Meeting of the Eastern Psychological Association, Baltimore, MD.

Gough, H. G. (1965). Conceptual analysis of psychological test scores and other diagnostic variables. Journal of Abnormal Psychology, 70, 294-302.

Gough, H. G. (1975). Manual for the California Psychological Inventory (rev. ed.). Palo Alto, CA: Consulting Psychologists Press.

Harris, M., Fontana, A. F., \& Dowds, B. N. (1977). The world hypotheses scale: Rationale, reliability, and validity. Journal of Personality Assessment, 41, 537-547.

Hart, J. J. (1982). Psychology of the scientist: XLVI. Correlation between theoretical orientation in psychology and personality type. Psychological Reports, 50, 795-801.

Heider, F. (1958). The psychology of interpersonal relations. New York: Wiley.

Hogan, R. (1976). Personality theory: The personological tradition. Englewood Cliffs, NJ: Prentice-Hall.

Hogan, R. (1986). Hogan Personality Inventory Manual. Minneapolis, MN: National Computer Systems.

Hogan, R., \& Cheek, J. M. (1983). Identity, authenticity, and maturity. In T. R. Sarbin \& K. E. Scheibe (Eds.), Studies in social identity (pp. 339-357). New York: Praeger.

Holland, J. L. (1985a). Making vocational choices (2nd ed.). Englewood Cliffs, NJ: Prentice-Hall.

Holland, J. L. (1985b). Professional Manual for the Self-Directed Search. Odessa, FL: Psychological Assessment Resources.

Holland, J. L. (1985c). Vocational Preference Inventory (VPI) Manual: 1985 Edition. Odessa, FL: Psychological Assessment Resources.

Johnson, J. A. (1981). The "self-disclosure" and "self-presentation" views of item response dynamics and personality scale validity. Journal of Personality and Social Psychology, 40, 761-769.

Johnson, J. A. (1983). Criminality, creativity, and craziness: Structural similarities in three types of nonconformity. In W. S. Laufer \& J. M. Day (Eds.), Personality theory, moral development, and criminal behavior (pp. 81-105). Lexington, MA: Heath.

Johnson, J. A. (1984, August). Personality correlates of the organicismmechanism dimension. Paper presented at the 92nd Annual Convention of the American Psychological Association, Toronto, Ontario, Canada.

Johnson, J. A. (1987a). Influence of adolescent social crowds on the development of vocational identity. Journal of Vocational Behavior, 31, 182-199.

Johnson, J. A. (1987b, April). Moderating effects of intraindividual variance across the trait descriptive universe. Paper presented at the $58 \mathrm{th}$ Annual Meeting of the Eastern Psychological Association, Arlington, VA.

Johnson, J. A., Cheek, J. M., \& Smither, R. (1983). The structure of empathy. Journal of Personality and Social Psychology, 45, 12991312.

Johnson, J. A., \& Hogan, R. (1981). Vocational interests, personality, and effective police performance. Personnel Psychology, 34, 49-53.

Jung, C. G. (1923). Psychological types (H. G. Baynes, Trans.). London: Kegan Paul.

Kelly, E. L. (1965). Review of the California Psychological Inventory. In O. K. Buros (Ed.), The sixth mental measurement yearbook (pp. 168-170). Highland Park, NJ: Gryphon Press.

Kelly, G. A. (1955). The psychology of personal constructs. New York: Norton.

Kleinmuntz, B. (1967). Personality measurement. Homewood, IL: Dorsey.

Knapp, R. H. (1964). An experimental study of a triadic hypothesis concerning the sources of aesthetic imagery. Journal of Projective Techniques, 28, 49-54.

Kolb, D. A. (1976). Learning Style Inventory: Technical Manual. Boston: $\mathrm{McBer} \& \mathrm{Co}$.

Kramer, D. A. (1983). Post-formal operations? A need for further conceptualization. Human Development, 26, 91-105.

Kramer, D. A., Goldston, R. B., \& Kahlbaugh, P. E. (1987, April). A measure of paradigm beliefs. Paper presented at the 58th Annual Meeting of the Eastern Psychological Association, Arlington, VA.

Krasner, L., \& Houts, A. C. (1984). A study of the "value" systems of behavioral scientists. American Psychologist, 39, 840-850.

Kuhn, T. S. (1962). The structure of scientific revolutions. Chicago: University of Chicago Press.

Lerner, R. M., \& Hultsch, D. F. (1983). Human development: A lifespan perspective. New York: McGraw-Hill.

Lorenz, K. (1977). Behind the mirror: A search for a natural history of human knowledge. (R. Taylor, Trans.). New York: Harcourt Brace Jovanovich.

Martin, J. E. (1982). Presentationalism: Toward a self-reflexive psychological theory. In W. B. Weimer \& D. S. Palermo (Eds.), Cognition and the symbolic processes: Vol. 2 (pp. 69-129). Hillsdale, NJ: Erlbaum.

McCain, G., \& Segal, E. M. (1988). The game of science (5th ed.). Pacific Grove, CA: Brooks/Cole.

Megargee, E. I. (1972). The California Psychological Inventory Handbook. San Francisco: Jossey-Bass.

Myers, I. B. (1962). Manual for the Myers-Briggs Type Indicator. Princeton, NJ: Educational Testing Service.

Nolf, B. (1986). The effect of the organismic and mechanistic world views on coping styles and locus of control. Unpublished senior honor's thesis, Pennsylvania State University, University Park.

Norman, W. T. (Chair) (1986, August). What are the basic dimensions of personality? Symposium conducted at the 94th Annual Convention of the American Psychological Association, Washington, DC.

Overton, W. F. (1975). General systems, structure, and development. In K. F. Riegel \& G. C. Rosenwald (Eds.), Structure and transformation: Development and historical aspects (pp. 61-81). New York: Wiley.

Overton, W. F. (1976). The active organism in structuralism. Human Development, 19, 71-86.

Pepper, S. C. (1942). World hypotheses. Berkeley: University of California Press.

Reese, H. W., \& Overton, W. F. (1970). Models of development and theories of development. In L. R. Goulet \& P. B. Baltes (Eds.), Life- 
span developmental psychology: Research and theory (pp. 115-145). New York: Academic Press.

Rokeach, M. (1960). The open and closed mind. New York: Basic Books. Rotter, J. B. (1966). Generalized expectancies for internal versus external control of reinforcement. Psychological Monographs, 80, 1-28.

Royce, J. R. (1974). Cognition and knowledge: Psychological epistemology. In E. C. Carterette \& M. P. Friedman (Eds.), Handbook of Perception: Vol. 1. Historical and philosophical roots of perception (pp. 149-176). New York: Academic Press.

Royce, J. R., Mos, L. P., \& Kearsley, G. P. (1975). Manual: PsychoEpistemological Profile (Forms V\&VI). Edmonton: Center for Advanced Study in Theoretical Psychology at the University of Alberta, Canada.

Rychlak, J. F. (1968). A philosophy of science for personality theory. Boston: Houghton Mifflin.

Santrock, J. W., \& Bartlett, J. C. (1986). Developmental psychology: A life-cycle perspective. Dubuque, IA: Wm. C. Brown.

Singer, B. F. (1971). Toward a psychology of science. American Psychologist, 26, 1010-1015.

Slife, B. D. (1987). Telic and mechanistic explanations of mind and meaningfulness: An empirical illustration. Journal of Personality, 55, 445-466.

Stolorow, R. D., \& Atwood, G. E. (1979). Faces in a cloud: Subjectivity in personality theory. New York: Jason Aronson.
Tomkins, S. S. (1965). Affect and the psychology of knowledge. In S. S. Tomkins \& C. E. Izard (Eds.), Affect, cognition, and personality: Empirical studies (pp. 72-97). New York: Springer.

Wardell, D., \& Royce, J. R. (1975). Relationships between cognitive and temperament traits and the concept of "style." Journal of Multivariate Experimental Personality and Clinical Psychology, 1, 244-266.

Wilson, J. (1980). Dialectical thought: The development of a self-conscious perspective on world knowing. Unpublished master's thesis, Pennsylvania State University, University Park.

Young, N. P. (1975). The psychology of explanation and the measurement of explanatory satisfaction. (Doctoral dissertation, Pennsylvania State University). Dissertation Abstracts International, 36, 5775B-5776B.

Zuckerman, M. (1979). Sensation-seeking: Beyond the optimal level of arousal. Hillsdale, $\mathrm{NJ}$ : Erlbaum.

Zuckerman, M. (1983). A biological theory of sensation-seeking. In M. Zuckerman (Ed.), Biological bases of sensation seeking, impulsivity, and anxiety (pp. 37-76). Hillsdale, NJ: Erlbaum.

Zuckerman, M. (1985). Sensation seeking, mania, and monoamines. Neuropsychobiology, 13, 121-128.

Received July 28, 1987

Revision received November 13, 1987

Accepted March 18, 1988 